\title{
Prevalence and risk factors of low bone mineral density in spondyloarthritis and prevalence of vertebral fractures
}

\author{
Sandrine Malochet-Guinamand ${ }^{1 *}$ (D) Bruno Pereira ${ }^{2}$, Zuzana Tatar ${ }^{1}$, Anne Tournadre ${ }^{1}$, Anna Moltó ${ }^{3}$, \\ Maxime Dougados ${ }^{3}$ and Martin Soubrier ${ }^{1}$
}

\begin{abstract}
Background: Investigate the prevalence and risk factors of low bone mineral density (BMD) in patients with axial spondyloarthritis as well as investigating the prevalence of vertebral fractures.

Methods: Patients underwent BMD measurements with dual-energy X-ray absorptiometry (DXA) in the anteriorposterior lumbar spine, lateral spine and hip. We screened for vertebral fractures using vertebral fracture assessment, and then checked for syndesmophytes on the VFA images. Sociodemographic and clinical variables were collected.

Results: A total of 89 patients ( $41,6 \%$ female) took part in the study with a mean age of $44 \pm 14$ years and disease duration $10.2 \pm 10.6$ years. According to World Health Organization (WHO) criteria, 48,3\% of patients displayed osteopenia and 6,7\% osteoporosis. In the subgroup of women who underwent measurement at all sites including the lateral spine, the prevalence of osteopenia was 39.3\% in the anterior-posterior spine, $32.1 \%$ in the lateral spine, and $64.3 \%$ with all sites together. VFA led to the diagnosis of at least one vertebral fracture in $6.2 \%$ of patients. On VFA, syndesmophytes were found in $24.3 \%$ of patients. The variables associated in multivariate analyses with low BMD in different measurement sites were low body mass index (BMI), a high physician's global assessment score, a high Bath Ankylosing Spondylitis Functional Index (BASFI) score and female gender.

Conclusion: Our study found a high prevalence (around 50\%) of low BMD in SpA. Conversely, the prevalence of osteoporosis (6.7\% according to WHO criteria) and vertebral fractures (6.2\%) was lower than generally reported in the literature. While lateral spine BMD measurement did little to improve the detection of osteopenia in women, the sample size was not large enough to enable us to draw definite conclusions.
\end{abstract}

Keywords: Bone density, Fractures, Ankylosing spondylitis

\section{Background}

Spondyloarthritis ( $\mathrm{SpA}$ ) is the second most common form of inflammatory arthritis after rheumatoid arthritis. The Assessment in SpondyloArthritis international Society (ASAS) classification criteria define axial and peripheral forms [1]. Although current treatment, particularly with the advent of biological therapies, usually makes it possible to manage the disease well, a certain number of comorbidities may affect functional prognosis

\footnotetext{
* Correspondence: smalochet@chu-clermontferrand.fr

'Rheumatology Department, Clermont-Ferrand University Hospital, 58 Rue

Montalembert, FR 63003 Clermont-Ferrand, France

Full list of author information is available at the end of the article
}

and alter quality of life. For instance, with a prevalence of $13 \%$, osteoporosis was the most common comorbidity found in SpA in the ASAS-COMOSPA cross-sectional international study [2]. Most of the studies also show that patients with axial SpA (axSpA) have a higher prevalence of osteoporosis than that expected in the general population [3].

The EULAR SpA imaging task force recommends screening for osteoporosis in SpA [4]. The standard technique for measuring bone mineral density (BMD) is dual energy X-ray absorptiometry (DXA). Measurements are usually taken in the femur and in the lumbar spine in the anterior-posterior projection. Spine BMD measurements 
in the anterior-posterior projection take in the entire vertebral body as well as the posterior arch. Because of this, any type of SpA-related spinal damage, in particular syndesmophytes and posterior arch damage, may influence the measurements by overestimating them, thereby challenging the interpretation of the exam. For this reason, in the advanced disease stages, it is suggested to perform DXA spine measurement in the lateral projection [4]. The newer-generation densitometry machines can perform lateral spine measurement while the patient is in a supine position. This technique proves to exhibit good precision [5]. However, there is little data on the use of lateral spine measurement regarding its relevance in routine practice for osteoporosis screening.

The prevalence of vertebral fractures has been shown to be increased in ankylosing spondylitis (AS) from the early stages onwards [6]. Such spinal fractures can easily go unnoticed, given that they are sometimes asymptomatic, or when spine pain is interpreted as a symptom pertaining to the AS. Vertebral fracture assessment (VFA) is a low-radiation technique that allows vertebral fractures to be screened using DXA [7]. This means that vertebral fractures can be checked for while bone mass is being assessed, which is particularly useful since BMD assessment may underestimate the risk of fractures in this patient population [8]. There is as yet little data on the use of this technique in SpA.

The aims of this study were to evaluate the prevalence and risk factors of low BMD in the anterior-posterior spine, lateral spine, and hip in axial SpA patients, as well as the prevalence of vertebral fractures by means of VFA.

\section{Methods}

\section{Population studied}

This is a monocentric observational, cross-sectional study in axial SpA patients who presented consecutively in our rheumatology department. Patients provided their written consent and were included if they met ASAS criteria for axial SpA according to the Rheumatologist and were more than 18 years of age. The study was approved by the local ethics committee "Ile de France III" (S.C 3004), and all patients provided their informed consent to participate in the study.

\section{Demographic, clinical and laboratory data was collected during the visit}

Demographic and clinical data included: Age, sex, weight, body mass index (BMI), smoking status (Never, history but cessation of more than 3 years, history but cessation of less or equal than 3 years, current smoker), consumption of alcohol, age at diagnosis, time since diagnosis, number of swollen joints, number of painful joints, physician's global assessment of disease activity (evaluation of the activity of the disease based on the information provided by the patient and the data collected), use of non-steroidal anti-inflammatory drugs (NSAIDs) (yes or no and if yes \% of days with NSAIDS intake), current prednisone intake (mg/day) and estimated total intake of corticosteroids from the beginning of the disease (mg), history of spinal fracture, history of peripheral fracture, calcium supplementation (never, past, current), vitamin D supplementation (never, past, current), anti-osteoporotic treatment (never, past, current), and disease activity and severity scores from the selfadministered questionnaires (Bath Ankylosing Spondylitis Disease Activity Index [BASDAI] and Bath Ankylosing Spondylitis Functional Index [BASFI]).

Laboratory data (i.e. sedimentation rate, C-reactive protein (CRP), and vitamin D levels) were also reported and also Sacroiliitis on plevic $\mathrm{X}$ rays (at least garde II bilateral or grade III unilateral: No; Yes; Non applicable or not done).

\section{BMD measurement}

All participants in our center underwent DXA BMD measurement in the anterior-posterior spine (L1 to L4), lateral spine (L2 to L4) and left hip (total hip and femoral neck), or in the right hip if the examination was not feasible in the left hip, for instance if there had been hip replacement. All measurements were conducted by technicians trained on the Hologic Discovery system according to the manufacturer's recommendations.

The results were expressed in BMD $\left(B M D \mathrm{~g} / \mathrm{cm}^{2}\right)$ as well as in a $\mathrm{Z}$ - and $\mathrm{T}$-score using the reference curves supplied by the manufacturer. The Z-score is the number of standard deviations above or below the values of healthy adults of the same age and same sex. The Tscore is the number of standard deviations above or below the values of young adults of the same sex.

There is no agreement on what defines low BMD in young adults. The International Society for Clinical Densitometry recommends using a Z-score of $\leq-2$ standard deviations as the threshold for low BMD in this population [9].

In postmenopausal women, and in men aged more than 50 years, the World Health Organization (WHO) defines osteopenia as a T-score of between -1 and -2.5 and osteoporosis as a T-score of $\leq-2.5$ [10]. Our study population was not large enough to apply both types of definition on the basis of age and menopausal status. We therefore extrapolated and used the WHO definitions for the entire study population.

For lateral spine BMD measurement, reference curves, and therefore $\mathrm{Z}$ - and $\mathrm{T}$-score data, are only available for women. Definitions of low bone mass and osteoporosis are the same as at other sites.

Vertebral fractures were checked for by means of VFA using the software supplied by the manufacturer. T4 to L4 were qualitatively analyzed and then semi-quantitatively 
analyzed using the Genant classification [11]. Quantitative analysis was then performed using the vertebral height measurement software supplied by the manufacturer. A physician trained in reading VFA read the VFA images and detected vertebrae deemed to be fractured. The height of vertebrae deemed to be fractured was then measured using the morphometry software supplied by the manufacturer. These vertebrae were then categorized according to severity by means of the Genant classification. Grade 1 (mild) was defined as a decrease in vertebral height (anterior, middle or posterior) of 20 to 25\%; Grade 2 (moderate) as a decrease in vertebral height of 25 to $40 \%$; and Grade 3 (severe) as a decrease in vertebral height of more than $40 \%$.

Additionally, as described by Aubry-Rozier in a pilot study, each intervertebral disk space from T12-L1 to L5-S1 was studied so as to check whether any syndesmophytes were present. In this study overall agreement beetween VFA and X-rays was excellent [12].

The machine was checked by the daily measurement of a phantom supplied by the manufacturer and sent to an authorized quality-control body.

\section{Statistical analysis}

All analyses were performed using Stata software (Version 13, StataCorp, College Station, TX) and were conducted for a two-sided Type I error of 5\%. Continuous data were presented as mean \pm standard deviation or median [interquartile range], and categorical parameters as the number of patients and associated percentages. To highlight the risk factors of low bone mineral density and of vertebral fracture assessment (in other words, in order to study the intensity of AP lumbar spine, femoral neck, total hip and lateral lumbar spine compared to patients' characteristics), analyses have considered usual statistical tests: [1] ANOVA or Kruskal-Wallis tests if the conditions for ANOVA were not met ((i) normality and (ii) homoscedasticity analyzed using Bartlett's test for the comparisons between gender, smoking status and Vitamin D supplementation followed when appropriate (omnibus $p$-value $<0.05)$ by post-hoc tests to take into account multiple comparisons (Tukey-Kramer's test after ANOVA and Dunn's test after Kruskal-Wallis), [2] correlation coefficients (Pearson or Spearman according to statistical distribution), applying Sidak's correction of type I error, for the study of relationships with other quantitative variables (age, BMI, disease duration, number of swollen joints, number of tender joints, ESR, CRP, physician's global assessment, percentage of days with NSAID intake, current vitamin D level, BASFI and BASDAI). When necessary, comparisons between categorical data were carried out by the Chi-squared test or, when appropriate, by Fisher's exact test. Then, multivariate analyses were performed to study the parameters associated to low bone mineral density and vertebral fracture assessment. More precisely, multiple linear regression models were performed using the stepwise approach (backward and forward) considering covariates selected according to univariate results and clinical relevance. The normality of residuals was studied as described previously and the results were expressed as regression coefficients and $95 \%$ confidence intervals.

\section{Results}

In total, 89 patients meeting the criteria for axial SpA participated in the study. There were 37 women (41.6\%) and 52 men $(58.4 \%)$. Their mean age was 44 years $( \pm 14)$ and they had a mean disease duration of 10.2 years $( \pm 10.6) .55(62 \%)$ patients had sacroilitis on pelvic X-rays (at least grade II bilateral or grade III unilateral).

The complete characteristics of the study population are summarized in Table 1.

When WHO definitions were applied to the entire population, $48.3 \%$ of patients exhibited osteopenia and $6.7 \%$ osteoporosis. When comparing the different sites, the femoral neck was the measurement site that most often enabled a diagnosis of osteopenia to be made (42.7\%, compared to $25.8 \%$ in the total hip and $31.8 \%$ in the anterior-posterior spine; $p=0.003)$. Five patients (5.6\%) had a Z-score $\leq-2$.

Overall, 28 of the 37 women underwent spine BMD measurement in the anterior-posterior projection and

Table 1 Population characteristics

\begin{tabular}{|c|c|}
\hline Variable & Mean \pm SD \\
\hline Age, years & $44.4 \pm 14$ \\
\hline \multicolumn{2}{|l|}{ Sex, number (\%) } \\
\hline Male & $52(58.4)$ \\
\hline Female & $37(41.6)$ \\
\hline Disease duration (years) & $10.2 \pm 10.6$ \\
\hline $\mathrm{BMI}\left(\mathrm{kg} / \mathrm{m}^{2}\right)$ & $26 \pm 4.2$ \\
\hline ESR (mm 1st H) & $10 \pm 9.5$ \\
\hline CRP (mg/dL) & $7.1 \pm 11.8$ \\
\hline Physician's global assessment (0-10) & $4.2 \pm 2.6$ \\
\hline Percentage of days with NSAID intake (\%) & $64 \pm 31.3$ \\
\hline Current vitamin D level (ng/mL) & $22.6 \pm 9.4$ \\
\hline BASFI score $(0-100)$ & $27.1 \pm 23.5$ \\
\hline BASDAI score $(0-10)$ & $6.1 \pm 4.8$ \\
\hline Femoral neck BMD $\left(\mathrm{g} / \mathrm{cm}^{2}\right)$ & $0.795 \pm 0.116$ \\
\hline Total hip BMD $\left(\mathrm{g} / \mathrm{cm}^{2}\right)$ & $0.926 \pm 0.121$ \\
\hline AP lumbar spine BMD $\left(\mathrm{g} / \mathrm{cm}^{2}\right)$ & $1.017 \pm 0.172$ \\
\hline Lateral lumbar spine BMD $\left(\mathrm{g} / \mathrm{cm}^{2}\right)$ & $0.926 \pm 0.121$ \\
\hline
\end{tabular}

$B M I$ body mass index, ESR erythrocyte sedimentation rate, CRP C-reactive protein, $B A S F I$ bath ankylosing spondylitis functional index, $B A S D A I$ bath ankylosing spondylitis disease activity index, $B M D$ bone mineral density 
lateral projection (the measurement was not performed at this site or was uninterpretable in 9). In total, $32.1 \%$ displayed osteopenia on lateral spine measurement and $39.3 \%$ osteopenia on anterior-posterior spine measurement. Osteopenia at at least one site was found in 57\% of these 28 women when the anterior-posterior spine and hip were taken into account. Lateral spine measurement detected two additional osteopenic patients with normal BMD in the hip and anterior-posterior spine (Table 2). The overall prevalence of osteopenia in this group was $64.3 \%$. In addition, the entire population displayed significantly lower spine BMD on lateral measurement than on anterior-posterior measurement $(0.809 \pm 0.134$ vs. $1 \pm 0.136 ; p<0.001)$. Women had lower BMD than men on total hip measurement $(0.89 \pm 0.11$ vs. $0.95 \pm 0.12 ; p=0.04)$.

\section{Vertebral fractures}

VFA analysis of the lateral spine was possible in 80 patients (data not available for four and non-analyzable for five). A fracture was detected in five patients (6.25\%), with a total of eight fractures detected. 2 fractures were detected in the 34 patients without sacroilitis $(5,9 \%)$ and 3 in the 55 patients with sacroilitis $(5,4 \%)$.

\section{Syndesmophytes}

Screening for syndesmophytes was possible in 78 patients, with syndesmophyte observed at at least one level in 19 of them (24.3\%). The most frequently involved level was T12/L1 (12 patients), with a mean of 1.7 levels affected.

Regardless of the site, no significant difference was found with respect to BMD or T-score when considering the two groups of patients according to whether they had or had not syndesmophytes. No significant association between BMD, regardless of the site, and the number of levels with syndesmophytes was observed.

\section{Factors associated with BMD according to site}

The association between BMD and the different risk factors has been summarized in Table 3 (expressed as

Table 2 Number of osteopenic female patients when considering the lateral lumbar spine and other measurement sites

\begin{tabular}{llll}
\hline & $\begin{array}{l}\text { Lateral lumbar } \\
\text { spine T score } \\
\geq-1 \text { SD, } n\end{array}$ & $\begin{array}{l}\text { Osteopenia at } \\
\text { lateral lumbar } \\
\text { spine, } n\end{array}$ & \\
\hline $\begin{array}{l}\text { T score } \geq-1 \text { SD in all } \\
\text { Other measurement } \\
\text { sites, } n\end{array}$ & 10 & 2 & 12 \\
$\begin{array}{l}\text { Osteopenia at at least one other } \\
\text { measurement site, } n\end{array}$ & 9 & 7 & 16 \\
\begin{tabular}{l} 
Total \\
\hline
\end{tabular} & 19 & 9 & 28 \\
\hline
\end{tabular}

correlation coefficient) and Table 4 (mean \pm SD and $p$ value for statistical tests.)

The variables that significantly correlated with low BMD were in the anterior-posterior spine, a low BMI, the number of painful joints, a high physician's global assessment score and a high BASDAI score; in the femoral neck, the variables correlated with low BMD were age, a low BMI, and a high BASFI score; in the total hip, these variables were low BMI, a high physician's global assessment score, and high vitamin D levels. Lastly, in the lateral spine, the number of painful joints, number of swollen joints, high physician's global assessment score, and high BASDAI score all correlated with low BMD.

Regardless of the site, there was no significant association between BMD and smoking status, the length of time the patient had suffered from the disease, laboratory signs of inflammation (sedimentation rate and CRP), the percentage of days taking NSAIDs, and vitamin D supplementation.

The variables that were associated with BMD at the different sites were analyzed using multiple linear regression. The results have been summarized in Table 5. The following were significantly associated with low BMD: in the anterior-posterior spine, low BMI and a high physician's global assessment score; in the femoral neck, low BMI and a high BASFI score; and in the total hip, low BMI, female sex, and the physician's global assessment score. No significant association was found with the lateral spine.

\section{Discussion}

Our study showed that $48 \%$ of patients being followed for axial SpA displayed osteopenia and 6.7\% osteoporosis according to WHO criteria. These results reveal a relatively low prevalence of osteoporosis in our population compared with the data published in the scientific literature. For instance, in a 2012 literature review, the prevalence of osteopenia according to the WHO definition was $54 \%$ in the spine and $51 \%$ in the hip, whereas that of osteoporosis at the same sites was 13 and $16 \%$ respectively [13].

The difference in the prevalence of osteoporosis observed in our study may be linked to the different characteristics of our study population. Our study included SpA patients as defined by the ASAS criteria, whereas the above-mentioned review included patients who were suffering from AS according to the modified New York criteria. In a more recent review involving 55 studies, the prevalence of osteopenia in patients with AS or SpA varied between 5 and $88 \%$, whereas that of osteoporosis ranged from 3 to $47 \%$ [3].

BMD was lower in the lateral spine than in the anterior-posterior spine. However, using lateral spine measurement did little to improve the detection of low 
Table 3 Variables correlation with BMD in differents measurement sites using univariated analysis

\begin{tabular}{|c|c|c|c|c|c|c|c|c|}
\hline & AP LS & $p$ & Femoral neck & $p$ & Total hip & $\mathrm{p}$ & Lateral LS & $p$ \\
\hline Age & $0.11^{a}$ & 0.31 & $-0.22^{a}$ & 0.03 & $-0.003^{a}$ & 0.97 & $-0.08^{a}$ & 0.52 \\
\hline BMI & $0.27^{a}$ & 0.01 & $0.24^{a}$ & 0.02 & $0.33^{a}$ & 0.002 & $0.05^{a}$ & 0.62 \\
\hline Disease duration & $0.02^{a}$ & 0.86 & $-0.17^{a}$ & 0.13 & $-0.13^{a}$ & 0.21 & $-0.02^{a}$ & 0.84 \\
\hline Number of swollen joints & $-0.20^{a}$ & 0.06 & $-0.005^{a}$ & 0.96 & $-0.10^{a}$ & 0.34 & $-0.25^{a}$ & 0.03 \\
\hline Number of tender joints & $-0.22^{a}$ & 0.04 & $-0.08^{a}$ & 0.47 & $-0.12^{a}$ & 0.25 & $-0.32^{a}$ & 0.005 \\
\hline ESR & $-0.0008^{a}$ & 0.99 & $-0.08^{a}$ & 0.44 & $-0.09^{a}$ & 0.37 & $0.02^{a}$ & 0.87 \\
\hline CRP & $0.12^{a}$ & 0.26 & $-0.05^{a}$ & 0.63 & $0.05^{a}$ & 0.67 & $0.13^{a}$ & 0.28 \\
\hline Physician's global assessement & $-0.24^{a}$ & 0.03 & $-0.20^{a}$ & 0.06 & $-0.21^{a}$ & 0.05 & $-0.25^{a}$ & 0.04 \\
\hline$\%$ of days with NSAID intake & $-0.003^{a}$ & 0.97 & $-0.16^{a}$ & 0.15 & $-0.11^{a}$ & 0.31 & $0.07^{a}$ & 0.57 \\
\hline Current vit D level & $-0.15^{a}$ & 0.16 & $-0.18^{a}$ & 0.09 & $-0.23^{a}$ & 0.03 & $-0.07^{a}$ & 0.56 \\
\hline BASFI & $-0.10^{a}$ & 0.37 & $-0.22^{a}$ & 0.04 & $-0.19^{a}$ & 0.07 & $-0.10^{a}$ & 0.41 \\
\hline BASDAI & $-0.26^{a}$ & 0.01 & $-0.17^{a}$ & 0.10 & $-0.19^{a}$ & 0.06 & $-0.29^{a}$ & 0.01 \\
\hline
\end{tabular}

${ }^{a}$ :correlation coefficient $[95 \% \mathrm{Cl}] ; \mathrm{p}, p$ value. $\mathrm{BMD}$, Bone mineral density; $\mathrm{AP}$, anterior-posterior; $\mathrm{LS}$, lumbar spine; $\mathrm{BMI}$, body mass index; $\mathrm{ESR}$, erythrocyte sedimentation rate; $\mathrm{CRP}, \mathrm{C}$-reactive protein; $\mathrm{BASFI}$, bath ankylosing spondylitis functional index; BASDAl, bath ankylosing spondylitis disease activity index

BMD in our study since it led to an osteopenia diagnosis in only additional two female patients who had not met criteria for osteopenia in the other measurement sites. Nor was lateral spine measurement more effective in our study than anterior-posterior spine measurement for screening for low BMD. This contrasts with MA Ulu et al. in patients with AS meeting the modified New York criteria in patients who had had the disease for more than 10 years, they showed that lateral and not anteriorposterior measurement was lower in patients than in controls [14]. In a study in AS patients lateral spine measurement led to more diagnoses of osteoporosis than did anterior-posterior spine measurement [15]. Nevertheless, these two studies do not answer the question of whether lateral spine measurement improves the prediction of osteoporosis compared with the combined use of hip and anterior-posterior spine measurements. For example, in two other studies using lateral spine measurement, hip measurement was just as discriminative, being lower in patients than in controls $[14,16]$.

The prevalence of vertebral fractures in our study was $6.25 \%$, a figure mostly lower than those reported in the literature. That said, the prevalence of vertebral fractures in SpA has been shown to vary greatly depending on the studies. A literature review found a prevalence of vertebral fracture in AS that varied between 4 and 41\% [17]. Vertebral fractures are often defined in studies as a reduction in vertebral height relative to the other vertebrae. But this takes no account of the deformities' etiology. Hence some deformities associated with the

Table 4 BMD comparaison between groups for qualitatives variables

\begin{tabular}{|c|c|c|c|c|c|c|c|c|}
\hline & \multicolumn{2}{|l|}{ AP LS } & \multicolumn{2}{|l|}{ Femoral neck } & \multicolumn{2}{|l|}{ Total hip } & \multicolumn{2}{|l|}{ Lateral LS } \\
\hline & $\mathrm{BMD} \mathrm{g} / \mathrm{cm}^{2}$ Mean $\pm \mathrm{SD}$ & $p$ & $\mathrm{BMD} \mathrm{g} / \mathrm{cm}^{2}$ Mean $\pm \mathrm{SD}$ & $p$ & $\mathrm{BMD} \mathrm{g} / \mathrm{cm}^{2}$ Mean $\pm \mathrm{SD}$ & $p$ & $\mathrm{BMD} \mathrm{g} / \mathrm{cm}^{2}$ Mean $\pm \mathrm{SD}$ & $p$ \\
\hline \multicolumn{9}{|l|}{ Gender } \\
\hline \multirow[t]{2}{*}{ Female } & $0.984 \pm 0.135$ & & $0.778 \pm 0.114$ & & $0.894 \pm 0.113$ & & $0.79 \pm 0.11$ & \\
\hline & & 0.24 & & 0.25 & & 0.04 & & 0.17 \\
\hline Male & $1.04 \pm 0.19$ & & $0.807 \pm 0.117$ & & $0.948 \pm 0.122$ & & $0.82 \pm 0.14$ & \\
\hline \multicolumn{9}{|l|}{ Smoking status } \\
\hline Never & $0.980 \pm 0.131$ & & $0.794 \pm 0.121$ & & $0.934 \pm 0.120$ & & $0.808 \pm 0.141$ & \\
\hline ces $>3$ years & $1.088 \pm 0.265$ & 0.47 & $0.797 \pm 0.102$ & 0.98 & $0.934 \pm 0.109$ & 0.78 & $0.831 \pm 0.154$ & 0.54 \\
\hline ces $\leq 3$ years & $1.048 \pm 0.578$ & & $0.804 \pm 0.089$ & & $0.888 \pm 0.098$ & & $0.892 \pm 0.074$ & \\
\hline Current & $1.016 \pm 0.138$ & & $0.796 \pm 0.127$ & & $0.921 \pm 0.134$ & & $0.790 \pm 0.120$ & \\
\hline \multicolumn{9}{|l|}{ Vitamin D suppl } \\
\hline Never, n (\%) & $1.015 \pm 0.15$ & & $0.805 \pm 0.093$ & & $0.927 \pm 0.103$ & & $0.814 \pm 0.128$ & \\
\hline Past, n (\%) & $1.016 \pm 0.12$ & & $0.783 \pm 0.138$ & & $0.921 \pm 0.140$ & & $0.814 \pm 0.148$ & \\
\hline Current, n (\%) & $1.029 \pm 0.275$ & 0.66 & $0.794 \pm 0.130$ & 0.58 & $0.927 \pm 0.129$ & 0.98 & $0.811 \pm 0.141$ & 0.93 \\
\hline
\end{tabular}


Table 5 Results from multiple linear regression analysis with BMD at different measuring sites

\begin{tabular}{lccc}
\hline & AP lumbar spine BMD & Total hip BMD $^{\mathrm{a}}$ \\
\hline BMI & $0.01[0.01 ; 0.02]$ & $0.01[0.01 ; 0.02]$ & $0.01[0.01 ; 0.02]$ \\
Gender & & & $0.04[0.01 ; 0.09]$ \\
(Male/female) & & $-0.01[-0.02 ; 0.0]$ \\
Physician's global assessement & $-0.01[-0.03 ;-0.01]$ & $-0.01[-0.02 ;-0.01]$ & - \\
BASFI & & & \\
\hline
\end{tabular}

${ }^{a}$ Regression-coefficient [95\%IC]. BMD bone mineral density, BMI body mass index, BASFI bath ankylosing spondylitis functional index

disease, may be deemed to be fractures if a morphometric technique is used without the images being read by an expert, and so lead to an overestimation of fractures. More recently, the VFA technique has been validated for screening for vertebral fractures, showing good agreement with semiquantitative reading of standard radiographs and excellent negative predictive value [7]. One study in AS patients showed on average, good agreement between VFA using DXA and radiographic interpretation [18]. Geusens et al. investigated the prevalence of vertebral fractures in SpA patients by means of the semiquantitative interpretation of standard radiographs and VFA. They employed the Genant method, and found an $11.8 \%$ prevalence of vertebral fractures on the radiographs along with good agreement between the two assessment modalities [19]. In a population with early SpA, $15 \%$ of patients had already suffered from at least one fracture as assessed by standard radiography [20]. However, the authors pointed out that the method they used for interpreting the radiographs did not enable them to distinguish between the causes of vertebral height reduction.

Lastly, in our study population, $23.4 \%$ of patients displayed syndesmophytes at at least one vertebral level on VFA analysis. We found no association between the presence of syndesmophytes and bone density or Tscore regardless of the site. In contrast, MA Ulu showed that AS patients with at least one syndesmophyte on standard radiography had lower BMD than the others in the lateral spine projection [14]. The modified Stoke Ankylosing Spondylitis Spine Score, or mSASSS, which evaluates AS-related radiographic lesions, is also a factor that may be associated with low BMD, particularly in the femoral neck or spine on volumetric analysis but not in the anterior-posterior projection [15]. This mSASSS may even be associated with increased BMD in the spine [21]. The lack of association between syndesmophytes and BMD in our study may be linked to the fact that most cases displayed moderate involvement. It is different from the results published by Wildberger et al. In this study men with syndesmophytes have a normal BMD spine T-score [22]. Furthermore, this assessment modality has not been sufficiently validated as yet and requires additional study.
In our study, BMD was lower in women than men in the total hip only. Depending on the site, the variables significantly associated with lower BMD were, on univariate analysis, age, female sex, lower BMI, number of painful joints, number of swollen joints, physician's global assessment, BASDAI, BASFI, and vitamin D levels; on multivariate analysis, they were sex, BMI, physician's global assessment and BASFI. These results are consistent with some of the data in the literature. Factors that have been described as being associated with BMD in SpA or AS include demographic variables, disease duration, and disease activity or severity. Eva Klingberg studied the prevalence of osteoporosis in AS by means of DXA including lateral spine measurements [14]. Low BMD was associated with age, disease duration, low BMI, inflammatory parameters, and structural parameters such as the mSASSS or a spinal mobility index like the Bath Ankylosing Spondylitis Metrology Index (BASMI). Disease monitoring indexes were not associated with low BMD. Cross-sectional studies have returned controversial results on the correlation between BMD, disease activity and inflammatory parameters [3] while some prospective studies have shown that bone loss is greater in the active forms of the disease [23, 24]. Signs of inflammation on magnetic resonance imaging are associated with lower BMD in patients with inflammatory back pain and symptoms suggestive of SpA [25] or in patients with early non-radiographic SpA [26].

The variable that was the most consistently and most strongly associated with low BMD in our study was low BMI, which is known to be a major risk factor for osteoporosis and fracture in the major international cohorts [27]. We also found that BMD at the femoral neck was inversely correlated with BASFI. Other studies have shown a high BASFI score to be a risk factor for low BMD $[14,16,21,28]$ but this has not been so in all studies $[15,25,29]$. A loss of mobility is also a classic risk factor for bone loss [30]. It can be assumed that disease-related changes in functional capacity may be one of the causes of bone loss in SpA.

However, we found no association in our study with certain parameters such as smoking, CRP, use of NSAIDs, and vitamin D supplementation. Although there is little data available on the use of NSAIDs, in the prospective 
study of the DESIR cohort of patients with recent inflammatory back pain, the use of NSAIDs was shown to prevent bone loss in the hip [31]. We didn't take into account post-menopausal status that was not available and could interfer with women bone density.

The utility of our study is that it investigated DXA BMD in patients with axial SpA regardless of disease severity or duration, that it included lateral spine measurement, and that VFA was performed in all cases, enabling the detection of fractures and analysis of syndesmophytes.

That said, our study displays several limitations. The relative small sample size limits the conclusions that can be drawn, specially associated factors and also prevalence of osteoporosis and fracture. For instance, a criticism can be made of our applying the WHO definitions of osteopenia and osteoporosis to the entire study population. Yet, we lacked the power to investigate both types of population separately, and very few patients (5.6\%) met the definition of low BMD based on a Z-score $\leq-2$.

\section{Conclusion}

Our study found a high prevalence (around 50\%) of low BMD in SpA in our center. Conversely, the prevalence of osteoporosis (6.7\% according to WHO criteria) and vertebral fractures $(6.25 \%)$ was lower than those usually reported in the scientific literature.

It appears essential to assess the standard risk factors for osteoporosis in this population.

Lateral spine BMD measurement did little to improve the detection of osteopenia in women. We need new toll to improve bone fragility detection in this population. TBS (Trabecular Bone Score) measures the bone texture, and could predict fracture risk independently of BMD in secondary causes of osteoporosis [32] and could be helpfull in AS [22]. It may also be worthwhile further defining which deformities should be taken as vertebral fractures in this patient population.

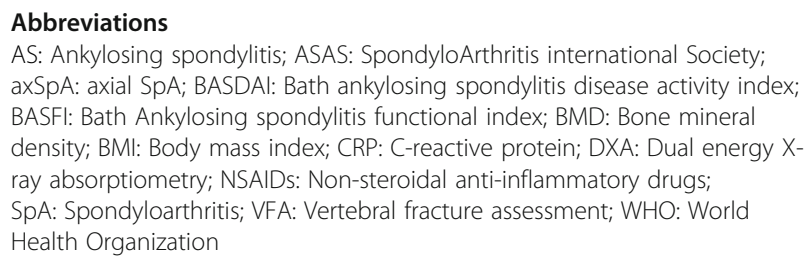

\section{Acknowledgments}

We thank Céline Lambert of the Biostatistics department for her precious help for formatting the results.

\section{Funding}

The authors have no support or funding to report.

\section{Availability of data and materials}

Data and supporting materials associated with this study will be provided upon request by the corresponding author.

\section{Authors' contributions}

SMG was responsible for the statistical analysis and interpretation, and wrote the article. BP contributed to the analysis and interpretation of data and has been involved in drafting the manuscript. AT contributed to the data collection and has been involved in revising critically the manuscript for important intellectual content; ZT contributed to the data collection and have been involved in revising the manuscript critically for important intellectual content. MS contributed to the data collection and has been involved in revising critically the manuscript for important intellectual content. AM and MD participated in the design of the study, contributed to the data collection and have been involved in revising critically the manuscript for important intellectual content. All authors have read and approved the final version of the manuscript.

Ethics approval and consent to participate

The study was approved by the local ethics committee "Ile de France III" (S.C 3004), and all patients provided their informed consent to participate in the study.

\section{Consent for publication}

Not applicable.

\section{Competing interests}

The authors declare that they have no competing interests.

\section{Publisher's Note}

Springer Nature remains neutral with regard to jurisdictional claims in published maps and institutional affiliations.

\section{Author details}

${ }^{1}$ Rheumatology Department, Clermont-Ferrand University Hospital, 58 Rue Montalembert, FR 63003 Clermont-Ferrand, France. ²Biostatistics unit (Clinical Research Direction), University Hospital of Clermont-Ferrand (CHU), Clermont-Ferrand, France. ${ }^{3}$ Rheumatology Department, Paris Descartes University, Cochin Hospital, AP-HP, Paris, France.

Received: 3 March 2017 Accepted: 11 August 2017

Published online: 22 August 2017

\section{References}

1. Rudwaleit M, van der Heijde D, Landewé R, Listing J, Akkoc N, Brandt J, et al. The development of assessment of SpondyloArthritis international society classification criteria for axial spondyloarthritis (part II): validation and final selection. Ann Rheum Dis. 2009:68:777-83.

2. Moltó A, Etcheto A, van der Heijde D, Landewé R, van den Bosch F, Bautista Molano W, et al. Prevalence of comorbidities and evaluation of their screening in spondyloarthritis: results of the international cross-sectional ASAS-COMOSPA study. Ann Rheum Dis. 2016;75:1016-23.

3. Kilic E, Ozgocmen S. Bone mass in axial spondyloarthritis: a literature review. World J Orthop. 2015;6:298-310.

4. Mandl P, Navarro-Compán V, Terslev L, Aegerter P, van der Heijde D, D'Agostino MA, et al; European League Against Rheumatism (EULAR). EULAR recommendations for the use of imaging in the diagnosis and management of spondyloarthritis in clinical practice Ann Rheum Dis 2015; 74: 1327-1339.

5. Blake GM, Jagathesan T, Herd RJ, Fogelman I. Dual X-ray absorptiometry of the lumbar spine: the precision of paired anteroposterior/lateral studies. Br J Radiol. 1994;67:624-30

6. Prieto-Alhambra D, Muñoz-Ortego J, De Vries F, Vosse D, Arden NK, Bowness $P$, et al. Ankylosing spondylitis confers substantially increased risk of clinical spine fractures: a nationwide case-control study. Osteoporos Int. 2015;26:85-91.

7. Rea JA, Li J, Blake GM, Steiger P, Genant HK, Fogelman I. Visual assessment of vertebral deformity by $x$-ray absorptiometry: a highly predictive method to exclude vertebral deformity. Osteoporosis Int. 2000;11:660-8.

8. Mitra D, Elvins DM, Speden DJ, Collins AJ. The prevalence of vertebral fractures in mild ankylosing spondylitis and their relationship to bone mineral density. Rheumatology (Oxford). 2000;39:85-9.

9. Lewiecki EM, Gordon CM, Baim S, Leonard MB, Bishop NJ, Bianchi ML, et al. International Society for Clinical Densitometry 2007 adult and Pediatric official positions. Bone. 2008;43:1115-21. 
10. Report of a WHO Study Group. Assessment of fracture risk and its application to screening for postmenopausal osteoporosis. World Health Organ Tech Rep Ser. 1994;843:1-129.

11. Genant HK, Wu CY, van Kuijk C, Nevitt MC. Vertebral fracture assessment using a semiquantitative technique. J Bone Miner Res. 1993:8:1137-48.

12. Aubry-Rozier B, Hans D, Krieg MA, Lamy O, Dudler J. Morphometric vertebral assessments via the use of dual X-ray absorptiometry for the evaluation of radiographic damage in ankylosing spondylitis: a pilot study. J Clin Densitom. 2014;17:190-4.

13. van der Weijden MA, Claushuis TA, Nazari T, Lems WF, Dijkmans BA, van der Horst-Bruinsma IE. High prevalence of low bone mineral density in patients within 10 years of onset of ankylosing spondylitis: a systematic review. Clin Rheumatol. 2012;31:1529-35.

14. Ulu MA, Cevik R, Dilek B. Comparison of PA spine, lateral spine, and femoral BMD measurements to determine bone loss in ankylosing spondylitis. Rheumatol Int. 2013:33:1705-11.

15. Klingberg E, Lorentzon M, Mellström D, Geijer M, Göthlin J, Hilme E, et al. Osteoporosis in ankylosing spondylitis -prevalence, risk factors and methods of assessment. Arthritis Res Ther. 2012;14:R108.

16. Mermerci Başkan B, Pekin Doğan Y, Sivas F, Bodur H, Ozoran K. The relation between osteoporosis and vitamin D levels and disease activity in ankylosing spondylitis. Rheumatol Int. 2010;30:375-81.

17. Geusens $P$, Vosse D, van der Linden S. Osteoporosis and vertebral fractures in ankylosing spondylitis. Curr Opin Rheumatol. 2007;19:335-9.

18. Vosse D, Heijckmann C, Landewé R, van der Heijde D, van der Linden S, Geusens P. Comparing morphometric X-ray absorptiometry and radiography in defining vertebral wedge fractures in patients with ankylosing spondylitis. Rheumatology (Oxford). 2007:46:1667-71.

19. Geusens P, De Winter L, Quaden D, Vanhoof J, Vosse D, van den Bergh J, et al. The prevalence of vertebral fractures in spondyloarthritis: relation to disease characteristics, bone mineral density, syndesmophytes and history of back pain and trauma. Arthritis Res Ther. 2015;17:294.

20. van der Weijden MA, van der Horst-Bruinsma IE, van Denderen JC, Dijkmans BA, Heymans MW, Lems WF. High frequency of vertebral fractures in early spondylarthropathies. Osteoporos Int. 2012;23:1683-90.

21. Kaya A, Ozgocmen S, Kamanli A, Ardicoglu O. Bone loss in ankylosing spondylitis: does syndesmophyte formation have an influence on bone density changes? Med Princ Pract. 2009;18:470-6.

22. Wildberger L, Boyadzhieva V, Hans D, Stoilov N, Rashkov R, Aubry-Rozier B. Impact of lumbar syndesmophyte on bone health as assessed by bone density (BMD) and bone texture (TBS) in men with axial spondyloarthritis. Joint Bone Spine. 2017;84:463-6.

23. Maillefert JF, Aho LS, El Maghraoui A, Dougados M, Roux C. Changes in bone density in patients with ankylosing spondylitis: a two-year follow-up study. Osteoporos Int. 2001;12:605-9.

24. Gratacós J, Collado A, Pons F, Osaba M, Sanmartí R, Roqué M, et al. Significant loss of bone mass in patients with early, active ankylosing spondylitis: a followup study. Arthritis Rheum. 1999;42:2319-24.

25. Briot K, Durnez A, Paternotte S, Miceli-Richard C, Dougados M, Roux C. Bone oedema on MRI is highly associated with low bone mineral density in patients with early inflammatory back pain: results from the DESIR cohort. Ann Rheum Dis. 2013;72:1914-9.

26. Akgöl G, Kamanlı A, Ozgocmen S. Evidence for inflammation-induced bone loss in non-radiographic axial spondyloarthritis. Rheumatology (Oxford). 2014;53:497-501.

27. De Laet C, Kanis JA, Odén A, Johanson H, Johnell O, Delmas P, et al. Body mass index as a predictor of fracture risk: a meta-analysis. Osteoporos Int. 2005;16:1330-8

28. Ghozlani I, Ghazi M, Nouijai A, Mounach A, Rezqi A, Achemlal L, et al. Prevalence and risk factors of osteoporosis and vertebral fractures in patients with ankylosing spondylitis. Bone. 2009;44:772-6.

29. Haugeberg G, Bennett AN, McGonagle D, Emery P, Marzo-Ortega H. Bone loss in very early inflammatory back pain in undifferentiated spondyloarthropathy: a 1-year observational study. Ann Rheum Dis 2010;69:1364-6.

30. Howe TE, Shea B, Dawson LJ, Downie F, Murray A, Ross C et al. Exercise for preventing and treating osteoporosis in postmenopausal women. Cochrane Database Syst Rev 2011 (7):CD000333. doi:10.1002/ 14651858.CD000333.pub2
31. Briot K, Etcheto A, Miceli-Richard C, Dougados M, Roux C. Bone loss in patients with early inflammatory back pain suggestive of spondyloarthritis: results from the prospective DESIR cohort. Rheumatology (Oxford). 2016;55:35-42.

32. Leslie WD, Aubry-Rozier B, Lamy O. Hans D; Manitoba bone density program. TBS (trabecular bone score) and diabetes-related fracture risk. J Clin Endocrinol Metab. 2013;98(2):602-9.

\section{Submit your next manuscript to BioMed Central and we will help you at every step:}

- We accept pre-submission inquiries

- Our selector tool helps you to find the most relevant journal

- We provide round the clock customer support

- Convenient online submission

- Thorough peer review

- Inclusion in PubMed and all major indexing services

- Maximum visibility for your research

Submit your manuscript at www.biomedcentral.com/submit 